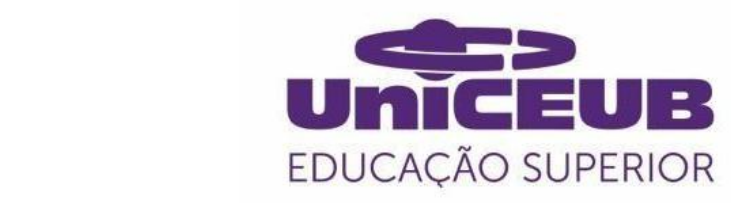

CENTRO UNIVERSITÁRIO DE BRASÍLIA- UnICEUB PROGRAMA DE INICIAÇÃO CIENTÍFICA

JULIANA STELA MARTINS ARAÚJO E CASTRO

PANORAMA DA ASSISTÊNCIA TÉCNICA EM HABITAÇÃO DE INTERESSE SOCIAL NO DISTRITO FEDERAL

BRASÍLIA

2020 


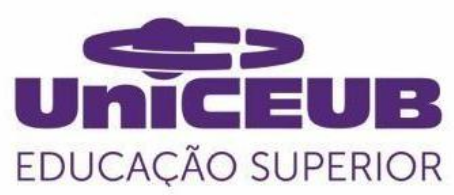

JULIANA STELA MARTINS ARAÚJO E CASTRO

\section{PANORAMA DA ASSISTÊNCIA TÉCNICA EM HABITAÇÃO DE INTERESSE SOCIAL NO DISTRITO FEDERAL}

Relatório final de pesquisa de Iniciação Científica apresentado à Assessoria de PósGraduação e Pesquisa.

Orientação: Msc. Ludmila Correia

\section{BRASÍLIA}




\section{AGRADECIMENTOS}

Agradeço à minha orientadora Ludmila, que também se tornou minha mentora na área de habitação social e aos colegas do Morada de Luz que caminharam e sonharam em conjunto. 


\section{RESUMO}

A contextualização e cenário de desigualdade social encontrado no Distrito Federal reporta a situações semelhantes em períodos de crescimento das metrópoles. O padrão é repetido, assim como nas demandas sociais e, em especial, as necessidades relacionadas à moradia. Pretende-se compreender o panorama social e histórico das atividades que antecederam as políticas de estado existentes em outras cidades e associa-las à realidade do Distrito Federal. Através da coleta de dados secundários, questionário online e análises a partir das referências bibliográficas para compreender o cenário de ATHIS atual no Distrito Federal, buscando, ainda, o histórico local. Portanto, o levantamento das entidades que realizam assistência técnica, junto às análises dos dados cedidos por instituições envolvidas permite a compreensão do cenário crescente em Brasília.

Palavras-Chave: Habitação social. Habitação Distrito Federal. ATHIS. 
LISTAS DE FIGURAS, TABELAS, QUADROS, GRÁFICOS, SÍMBOLOS E ABREVIAÇÕES

\author{
APO - Avaliação pós-ocupação \\ ATHIS - Assistência Técnica de Habitação de Interesse Social \\ HIS - Habitação de Interesse Social \\ CODHAB - Companhia de Habitação do Distrito Federal \\ IAB - Instituto dos Arquitetos do Brasil \\ DF - Distrito Federal \\ CAU - Conselho de Arquitetura e Urbanismo \\ AU - Arquitetura e Urbanismo
}


SUMÁRIO

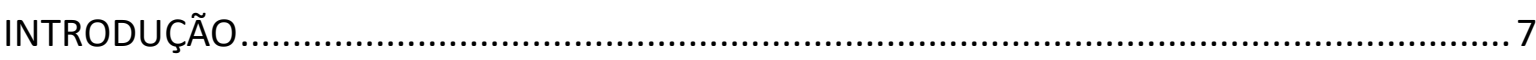

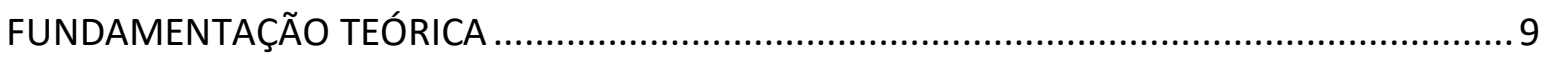

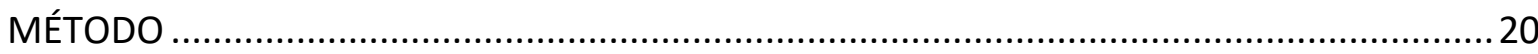

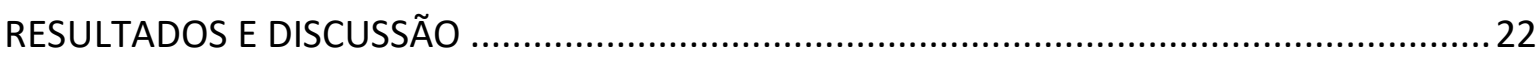

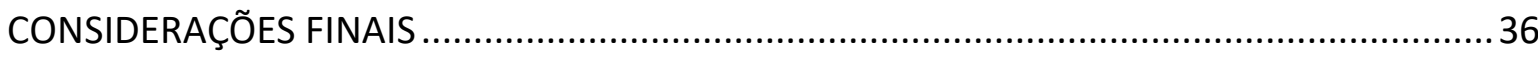

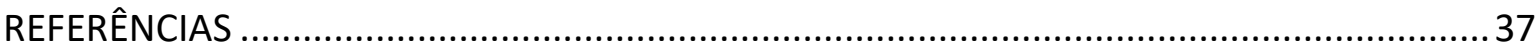




\section{INTRODUÇÃO}

O contexto social do Distrito Federal, tem seus níveis de desigualdade elevados desde a construção e fundação da capital. O Índice de Gini do Distrito Federal, responsável por classificar a concentração de renda em poucas famílias, atingiu 0,582 , após no ano anterior ter conquistado 0,578 (CODEPLAN, 2014). O crescimento populacional acerbado somado às condições em que os construtores foram assentados -em áreas periféricas- gerou a setorização classista e a falta de infraestrutura urbana necessária fora do Plano Piloto.

A pesquisa do IPEA de 2013 posicionou Brasília na terceira posição entre as cidades com maior déficit domiciliar, representando mais de 150 mil famílias entre as situações de precariedade, coabitação, excedente de aluguel -valor do aluguel compromete mais que $30 \%$ da renda familiar- ou adensamento excessivo. Para Ferreira (2015) situações de baixa mobilidade entre classes, exige ação maior por parte do Estado.

O cenário descrito por Ferreira pode ser enquadrado no DF ao considerar que, segundo a Pesquisa Distrital por Amostra de Domicílios (PDAD) de 2018, o grupo de moradores residentes em áreas mais periféricas, como Itapoã, Fercal, Estrutural e Varjão com renda domiciliar mensal média de aproximadamente $2.400,00$, enquanto no grupo de alta renda Lago Sul, Lago Norte, Plano Piloto, Sudoeste, entre outros- concentram em quantidades semelhantes de moradores mais de $15.000,00$

Em meio ao cenário atual, a Lei $11.888 / 2008$ assegura às famílias de baixa renda o direito a assistência técnica gratuita para projetos de arquitetura e obra. Para tanto, houveram criações de departamentos dentro dos governos estaduais e do DF para regulamentar essa ação, sendo os níveis de famílias em situação de precariedade habitacional elevados e os investimentos públicos escassos, as reformas em habitações da população de baixa renda é, ora insuficiente, ora indisponível pela quantidade desproporcional de candidatos e profissionais da área.

Portanto, o Distrito Federal e seu cenário de concentração das riquezas em algumas poucas famílias e falta de condições para a maioria tende a ser local com alta demanda de Assistência Técnica de Habitação Social -como confirmado a seguir no estudo- e com poucas ofertas do serviço, também em análise no estudo. 


\section{OBJETIVOS}

O objetivo central da pesquisa compreender os desafios da Assistência Técnica de Habitação de Interesse Social no DF, a partir do estudo territorialidade de demandas e ofertas. Os objetivos específicos são:

- Mapear a demanda e possível oferta de ATHIS por profissionais de arquitetura, a partir de cadastros junto à Companhia de Habitação do DF (CODHAB) e de registros de responsabilidade técnica junto ao Conselho de Arquitetura e Urbanismo

- Avaliar o acesso à informação e à atuação na área de ATHIS por parte de estudantes e profissionais da construção civil; 


\section{FUNDAMENTAÇÃO TEÓRICA}

O Brasil destaca-se por seu alto índice de desigualdade social. Segundo o IBGE, em 2018 , apenas $1 \%$ da população possui a renda mensal 33,8 vezes maior que metade das famílias brasileiras. Esse número exemplifica a situação em que coloca o país em uma posição abaixo dos vizinhos Argentina, Uruguai e México no índice de Gini (medidor de desigualdade social e concentração de renda).

Este cenário como herança dos tempos coloniais escravocratas e da abolição da escravidão sem qualquer auxílio governamental ou individual aos que deixavam de ser escravos e eram despejados das senzalas, para Filho (2006), as leis abolicionistas aumentaram os povoados e vilas em realidades precárias de habitação e infraestrutura urbana. O fim do Império e início da República segue em abstenção quanto aos déficits habitacionais, em contrapartida, o aumento dos empregos nas grandes capitais criaram uma alta demanda habitacional, gerando moradias irregulares sem acesso aos equipamentos urbanos ou serviços de iluminação e saneamento. Apenas após a década de 1930, no governo Vargas que surgem políticas estadistas voltadas à questão habitacional. Além da mudança de influência do setor que anteriormente era controlado majoritariamente pelos setores privados.

O caráter populista e estadista de Vargas em conjunto aos surtos de febre amarela e cólera que ocorreram em grande escala nas capitais cariocas e paulista trouxeram ao país ações higienistas. Apesar das políticas antidemocráticas que excluíram cortiços e casas em situação de risco dos centros, as ações trouxeram obras de saneamento básico e a tomada de posse de empresas de distribuição de energia, gás e telefonia. Vargas tem como mérito, ainda a Lei do Inquilinato, criada em 1942 para diminuir o impacto que os alugueis consumiam das rendas mensais.

A criação do Instituto de Aposentadoria e Pensões (IAP) passou a concentrar os recursos previdenciários no Estado, portanto, foi responsável pela ampliação habitacional que têm certo com vínculo com habitação social. Os conjuntos residenciais do Pedregulho e da Gávea, projetos de Affonso Reidy construídos em 1947 e 1950, representam este momento. O conjunto do Pedregulho abriga mais de 320 unidades, além de serviços como lavanderia, educação básica, centro de saúde, ginásio e área de lazer comum. O projeto tinha como cliente a Prefeitura do Rio de Janeiro, com intuito de ser voltado aos funcionários municipais. Apesar do caráter não envolver o público de baixa renda, Pedregulho foi uma realização importante 
na arquitetura social e, para Bonduki (2016 p. 142), "de grande relevância para a arquitetura brasileira e para a origem das políticas sociais de habitação". Atualmente, são estudados novamente os edifícios multifamiliares voltados às regiões periféricas.

Os governos seguintes ao de Vargas não apresentaram políticas ou programas habitacionais, apenas após o golpe de 1964, durante o regime militar, foram criados instituições de financiamento da casa própria, ação que não teve sucesso pela alta inflação e, portanto, impossibilidade da maior parte da população em financiar um imóvel. Após alguns anos foram criados programas que financiaram habitações para classes mais baixas.

O fim do regime militar seguiu sem priorizar a questão habitacional, ignorando a constante migração da população do campo para a cidade, assim como o crescimento populacional. Apenas a segunda metade da década de 1990, sob gestão de Fernando Henrique Cardoso, os financiamentos habitacionais voltaram a acontecer, com concentração na Caixa Econômica Federal, e com base no FGTS. Em seguida, o governo Lula amplia os programas habitacionais e obras de infraestrutura, como de saneamento básico, sob financiamento nacional e estadual. Foram criados, ainda, o Ministério das Cidades, em 2003, Sistema Nacional de Habitação (SNHIS), em 2005, e em 2009, o Programa Minha Casa Minha Vida (PMCMV).

Outras metrópoles brasileiras possuem históricos de ações de assistência técnica mais antigas que na capital. A prefeitura do Rio de Janeiro promove desde a década de 1990 o Favela-Bairro, programa de ATHIS que utiliza de reformas e planejamento urbano dentro das comunidades, assim como ações voltadas aos moradores. O programa que dura por quase três décadas promove ainda a participação da população, por mutirões, para ressignificar os espaços urbanos. Para Mendes (2006), "A metodologia desenvolvida pelo programa parece representar o modelo de urbanismo na cidade, baseado nos conceitos do planejamento urbano estratégico".

Nabil Bonduki (2013), em sua tese de doutorado descreve os processos que São Paulo percorreu e segue em jornadas de assistência técnica. $\mathrm{O}$ arquiteto e urbanista destaca que a possibilidade do autoempreedimento da casa tornou-se sonho pela maioria dos trabalhadores. Os alugueis, mesmo após as intervenções estatais de congelamento de preços, consumiam parte da renda familiar, enquanto os espaços cedidos ou alugados não proporcionavam espaços moldados às necessidades, portanto, os moradores que se adaptavam às residências. 
A condição de desigualdade social é acentuada no DF. A unidade federativa possui o maior IDH do país, de 0,824 (IBGE, 209). A classe de muito elevado deveria representar a qualidade de vida entre os habitantes, no entanto, este indicativo é maquiado pelo alto padrão de vida de alguns em detrimento da pobreza e escassez de recursos encontrados por outros. No caso do DF, é possível delimitar em área concêntrica, partindo do Eixo Monumental, enquadrando o Plano Piloto é delimitado o primeiro quadrante de alto padrão e à medida que se afasta do centro são encontrados os centros urbanos periféricos. Pode-se acrescentar, ainda, como parte da metrópole de Brasília as cidades ao seu entorno que, apesar de serem enquadradas fisicamente como Goiás, Minas Gerais e Bahia, fazem parte da economia brasiliense.

A construção da nova capital federal teve objetivo de gerar espaços igualitários e acessíveis à nova comunidade. No entanto, ainda durante a construção, os próprios trabalhadores que migraram de outras regiões brasileiras foram retirados dos acampamentos locados no centro e colocados em regiões periféricas, como o Núcleo Bandeirante. Após a inauguração da capital, a chegada de imigrantes de baixa renda seguia em crescimento, rapidamente criando novos assentamentos urbanos, ainda periféricos. Este cenário contínuo demonstra a segregação que acontece, desde a construção, em Brasília.

A imaturidade de Brasília aliado ao foco na população de alto padrão faz com que os índices de déficit habitacional, moradias precárias e insalubridade tornem-se questões discutidas apenas recentemente. Apenas em 2007 cria-se a Companhia de desenvolvimento habitacional do Distrito Federal (CODHAB) vinculada à Secretaria de estado de desenvolvimento urbano e habitação (SEDUH). O déficit habitacional do DF é concentrado na coabitação familiar e ônus excessivo com aluguel, ambos causados pela falta de moradia próxima ao centro comercial e desigualdade entre salários dos trabalhadores, gerando o abismo de valores entre áreas valorizadas e periferias.

O CAU-DF realizou uma pesquisa em que foi constatada a ausência de arquitetos nas construções e reformas. No Centro-Oeste apenas $15 \%$ da população que realizou intervenções habitacionais estiveram sob auxílio profissional. Isto é, a moradia digna -garantida pelo Artigo 60 da Constituição Federal- tornou-se um serviço inacessível para maior parte da população.

Descrita por Melo (2019) que "a habitação é não só o elemento estruturante da paisagem urbana como a peça que organiza o território nacional" reporta ao fato de que as residências, individualmente, compõem o espaço democrática da cidade. Dessa forma, as 
ações dos arquitetos e urbanistas encontram-se intrínsecas aos processos de planejamento urbano e soluções aos problemas habitacionais. Sobreira (2013) descreve a "estratégia do não planejamento" como uma tática de isolar e tornar autônomos os planos de reformas urbanas com interesses particulares e, portanto, contribuindo para a estratificação das cidades.

No caso do Distrito Federal são observados que, entre os maiores problemas habitacionais encontrados, estão inadequação de moradias, carência de infraestrutura, adensamento excessivo e ônus excessivo com aluguel. O gráfico de déficit habitacional por regiões do Brasil, realizado pela Fundação João Pinheiro representa, em todo Centro-Oeste, a dificuldade em gasto excessivo dos moradores com aluguel -são consideradas famílias que comprometem $30 \%$ de sua renda mensal com a finalidade citada. As regiões com maior custo de vida -como Sul, Sudeste e Centro-Oeste- apresentam em sua maior dedicação o ônus excessivo com aluguel.

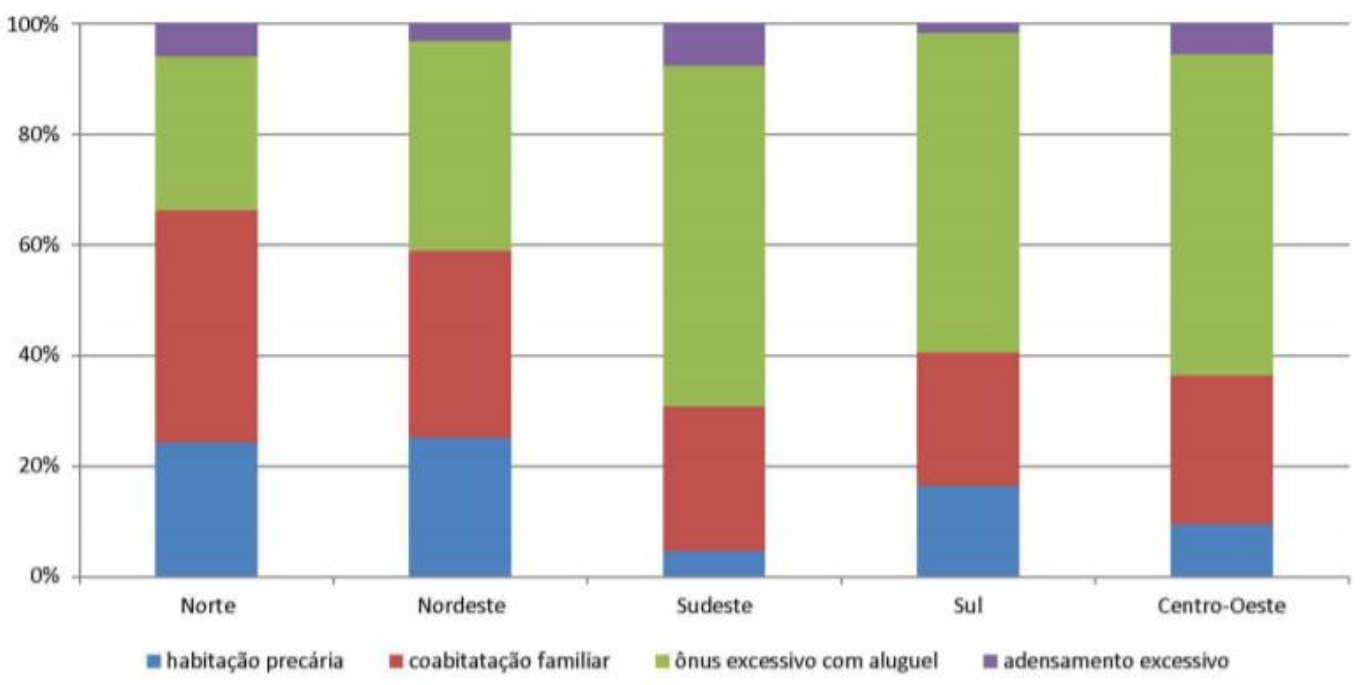

Gráfico 01 - Déficit habitacional por regiões brasileiras.

Fonte: Fundação João Pinheiro 


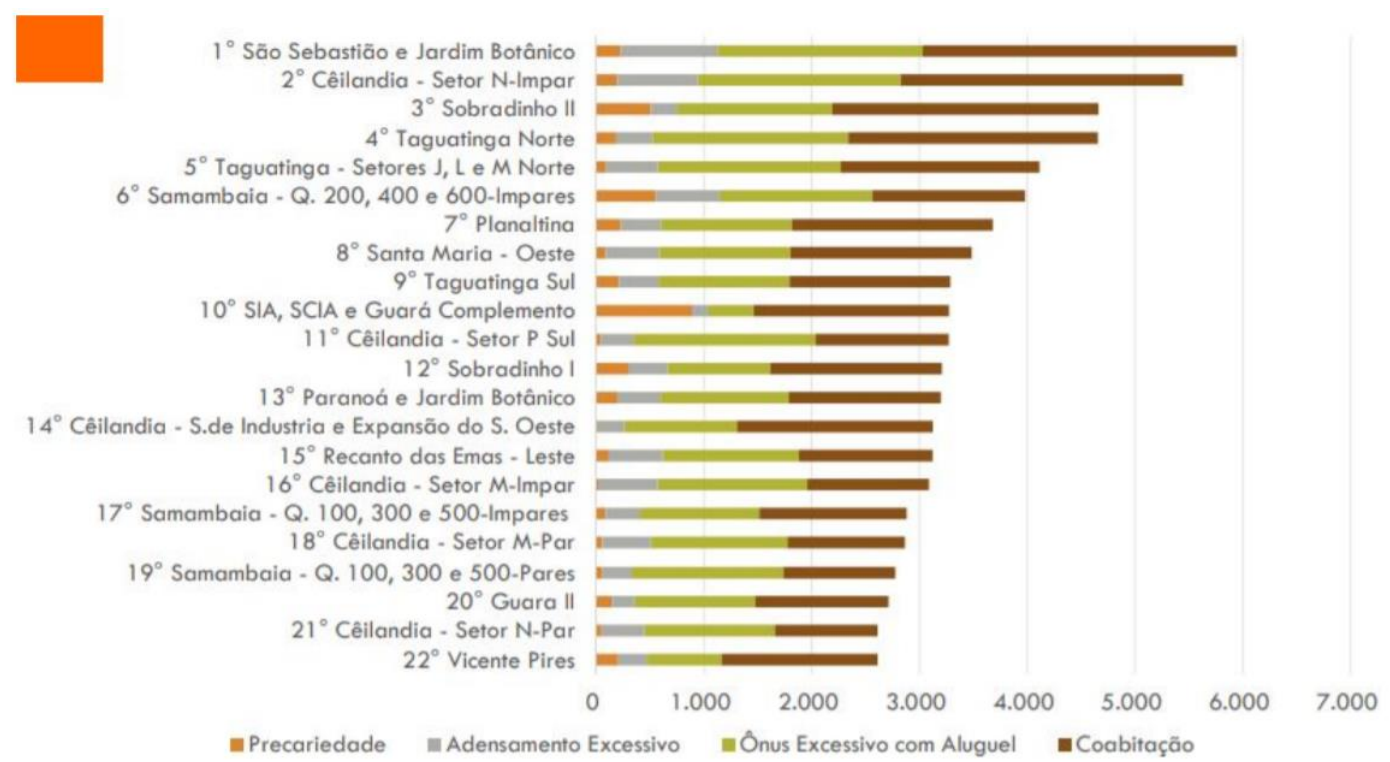

Gráfico 02 - Déficit habitacional por regiões administrativas.

Fonte:

A CODHAB atua em postos comunitários nas regiões de maiores demandas, como Sol Nascente e São Sebastião. A empresa pública realiza serviços de projeto arquitetônico e financiamento e realização de reformas. O cenário da capital, ainda emergente na área de ATHIS, cresceu em sua visibilidade nos últimos 3 anos a partir da realização de cursos de capacitação na área, organizados e financiados pelo Conselho de Arquitetura do Distrito Federal (CAU-DF).

Para Bonduki (2013) “A casa representava a segurança de um abrigo permanente; a garantia de morar, a médio prazo, praticamente a custo zero; a possibilidade de afeurir uma renda extra com a sublocação de cômodos no lote" e ainda "permitia, ainda, amoldar a casa aos desejos da família, incorporando trabalho e recursos num bem que se valorizava".

O Distrito Federal possui crescente aumento nos atendimentos à população que precisa, em especial após a criação da Companhia de desenvolvimento habitacional do Distrito Federal (CODHAB) em 2007. A empresa, atualmente, mantém postos de assistência técnica por algumas das regiões de maior carência do DF.

Além da empresa distrital, existem as ações que partem da sociedade civil em tempos esporádicos e sem formalização, podem ser encontradas em vaquinhas virtuais e ações institucionais. O serviço de assistência técnica ofertado de forma gratuita cresce em formato de coletivos e empresas privadas -que participam de concursos e realizam os projetos urbanos e arquitetônicos-. 
O crescimento das políticas públicas voltadas à habitação social emerge a necessidade da compreensão do resultado final e a vivência que o indivíduo adquire no espaço projetado. Nasce na Europa pós-segunda guerra mundial, durante a reconstrução das cidades e do próprio movimento moderno. Os primórdios das formas de APO (Análise Pós Ocupação) aparecem no II CIAM (Congresso Internacional de Arquitetura Moderna), em Frankfurt em 1929, com tema "A moradia para o mínimo nível de vida" para que houvesse a discussão sobre o estado precário em que os trabalhadores viviam, em análise às habitações existentes.

Surge apoiando-se em outras áreas, especialmente a Psicologia Ambiental -análise do impacto que o ambiente construído tem sobre o indivíduo. Analisa as experiências, sensações e emoções humanas geradas em determinado espaço, com intuito de determinar se as experimentações ocorrem por fatores biológicos ou externos-. Trata-se de conjunto de técnicas quantitativas e qualitativas, importando, portanto, as análises técnicas de vistorias, inspeções e desempenhos físicos determinados por normas ou recomendações.

Devido ao cenário pandêmico no ano de 2020, as atividades relacionadas à APO que precisariam de contato físico com os moradores foram suspensas para não comprometer a saúde de nenhum dos lados da pesquisa. As entrevistas foram realizadas integralmente online e, no entanto, restringiram-se aos profissionais da área de construção civil que compreendem os processos. Para a compreensão aprofundada sobre atividades de ATHIS foram buscadas arquitetas que trabalham na área.

Por fim, a bibliografia relacionada a APO tornou possível o contato e análise das respostas, ainda que totalmente virtual, dos profissionais que participaram. Os dados cedidos pelas instituições colaboradoras também seguiram analises quantitativas e qualitativas, considerando o conjunto da obra e o contexto socioeconômico do DF.

As pesquisas guiadas pelo professor Dr. César Imai, na Universidade de Londrina (Villa, Ornstein, 2013), estabeleceu que a relação dos moradores junto ao profissionais de arquitetura desde as primeiras etapas e, principalmente, com a participação ativa na execução da residência torna os erros de obras toleráveis, a compreensão de gastos e cortes, além do bem-estar maior com os ambientes, considerando que a residência é resultado direto de sua ação. Verificou-se, ainda, que no período de moradia os residentes compreendem melhor os processos construtivos, as manutenções e usos, gerando, portanto, racionalização consumo de água e outros recursos. 
Imai defende, ainda, que projetos de habitação social em larga escala tem menor personalização e adequação às necessidades especificas de cada morador. São soluções eficazes em situações de extrema urgência, como áreas irregulares e comunidades que construíram por autoconstrução. "Compreender que usuários possuem expectativas diferenciadas, além de ações individualizadas, podem contribuir para evitar reformas ineficientes e não planejadas" (Villa, Ornstein, 2013 p. 75).

Para Villa (2013), os resultados devem ser arquivados em uma base de dados que podem ser consultados para projetar. O foco da análise deve ser sobre a funcionalidade dos espaços e o comportamento do usuário diante das escolhas arquitetônicas. Devem ser considerados ainda os padrões culturais, privacidade, personalização, segurança, aspectos de topografia e clima, dentre outros aspectos técnicos. Portanto, para compreender os resultados da APO é necessário buscar os resultados subjetivos das experimentações de cada indivíduo com o espaço e juntá-los aos resultados técnicos obtidos a partir de levantamentos nos locais e medições de temperatura, umidade, aberturas, entre outros.

Para o profissional da construção civil existe o desafio, em Habitação de Interesse Social (HIS), de pontuar os principais problemas técnicos das residências, buscando manter equilíbrio entre tempo, orçamento e necessidades urgentes e sonhos dos próprios clientes. Para isso, a Análise pós-ocupação tem sido utilizada como identificador dos resultados tanto quantitativos, auxiliando na análise de orçamentos, gráficos de alcance e outros; e, em foco, qualitativos. O último engloba fatores mais complexos envolvendo fatores subjetivos.

Correia (2010, pg. 21) pontua que "Em HIS as condições restritivas de seus usuários requerem projetos ainda mais integrados ao ambiente, que minimizem as demandas ambientais, econômicas e sociais". Exige-se, portanto, um entendimento maior sobre as necessidades e possibilidades já alcançadas e possíveis em moradias de baixa renda. Correia ressalta, ainda, a importância de projetar voltado ao conforto ambiental e, dessa forma, aumentando os níveis de saúde e satisfação da população.

Para APO, é preciso balancear as necessidades totais e especificas dos moradores com as condições financeiras e sociais. No Rio Grande do Sul foram feitas pesquisas em conjuntos de HIS, para os pesquisadores "pesquisas indicam que os altos níveis de satisfação global obtidos nessas avaliações se devem a situação contextual e não necessariamente à qualidade construtiva da moradia e seus níveis de conforto ambiental" (Kowaltowski et al., 2006). 
Em análises sobre percepção, as questões analisadas devem tomar não apenas laudos técnicos, apesar de ter suma importância, mas necessita-se dos dados em conjunto às conclusões que os usuários do espaço referenciado. Minayo (2009) descreve uma pesquisa qualitativa como "trabalha com o universo dos significados, dos motivos, das aspirações, das crenças, dos valores e das atitudes". Portanto, tanto o contexto social quanto espacial em que os moradores do Distrito Federal, assim como a cultura local interferem na avaliação de boa arquitetura.

Além disso, a Coletânea Habitare (Abiko; Ornstein, 2002) apresenta diversos métodos e abordagens aplicadas com métodos e técnicas de desempenho. Dentre as etapas aplicadas, encontraram-se as entrevistas com os moradores e o levantamento físico de informações analisando desempenho ambiental, materiais, ergonomia, acessibilidade, entre outros-.

Por fim, o cenário mundial de pandemia com a Covid-19 voltou os esforços de APO conceitual -para segurança dos envolvidos na pesquisa e dos próprios moradores não foram envolvidos encontros presenciais. Para APO e Psicologia Ambiental são necessários os contatos diretos com entrevistados, em especial com moradores de baixa renda e escolaridade -assumindo as dificuldades de acesso aos meios de comunicação-. Portanto, as entrevistas em formatos de formulários online foram voltadas aos profissionais envolvidos em HIS, como arquitetos, engenheiros, assistentes sociais.

As formas que a CODHAB atua estão os postos comunitários com atendimento de assistentes sociais e arquitetos, seleção e classificação das residências e moradores para classifica-los em grupos de urgência, editais de terceirização dos serviços de projeto e acompanhamento de obra, junto ao financiamento da obra. Atualmente, a CODHAB possui dois programas em vigência, o primeiro de Melhorias -com exclusividade aos moradores que já têm casas como propriedade, mas que são classificados em grupos de risco -seja por problemas de estrutura da residência, saúde, mobilidade ou acessibilidade dos moradores-, e os programas de loteamento e entrega de projetos. Atuam, ainda, com melhorias urbanas recorrendo aos mutirões comunitários. 


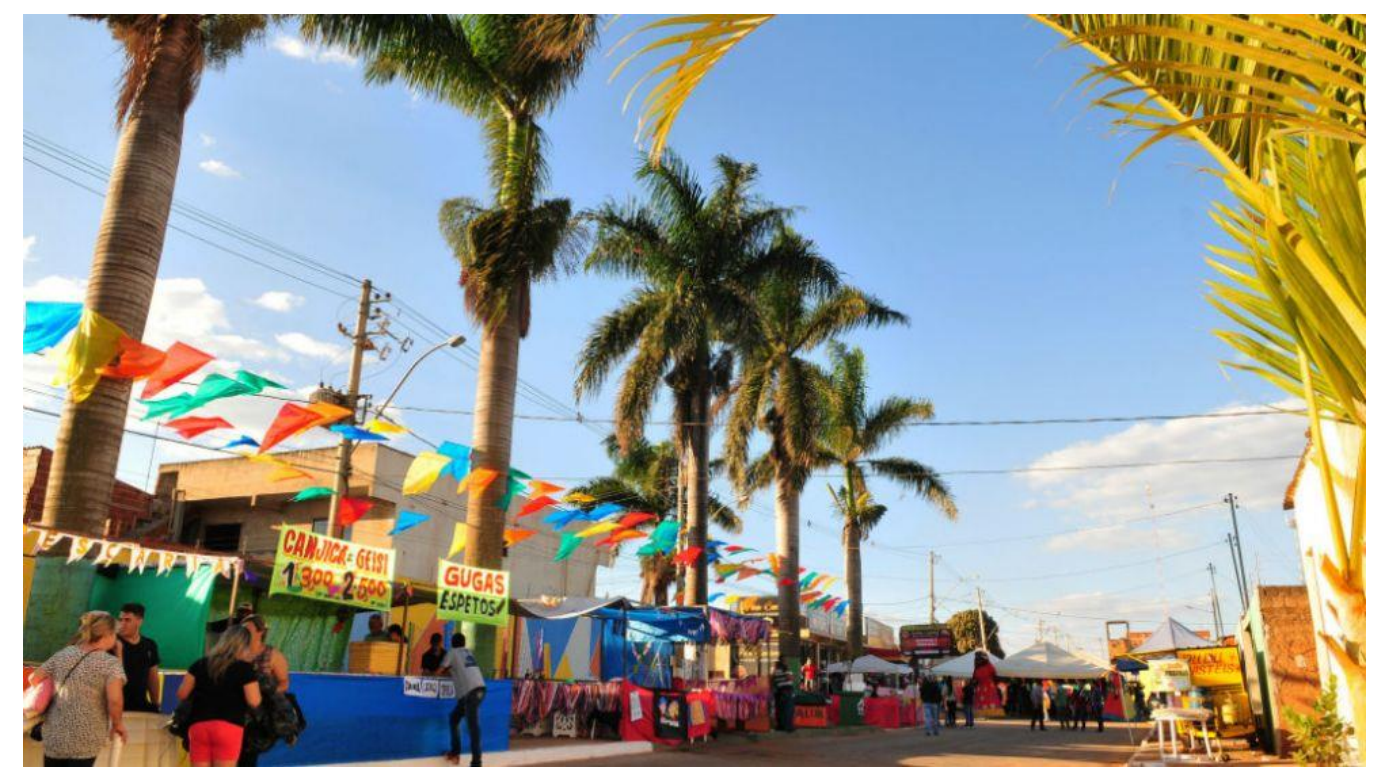

Figura 01 - Rua das palmeiras no Sol Nascente

Fonte:https://brasiliadefato.com.br/destaque/2017/07/avenida-das-palmeiras-einaugurada-no-sol-nascente/

No meio acadêmico dos cursos de Arquitetura e Urbanismo (AU) em todo o Brasil são poucas iniciativas voltadas a ATHIS. Segundo uma pesquisa realizada por Porangaba (2019), entre os 32 cursos de Universidades Federais apenas 7 seguem compromisso com o problema de HIS dentro do ambiente acadêmico.

No Distrito Federal foram encontradas iniciativas extracurriculares de alunos e professores tanto na Universidade Federal quanto na Instituição privada. A Universidade de Brasília possui, desde 2002, como Escritório Modelo de Arquitetura e Urbanismo (EMAU), o Centro de Ação Social em Arquitetura Sustentável (CASAS). Coordenado pela professora Liza Andrade, o EMAU desenvolve projetos junto às comunidades que não possuem acesso aos serviços de arquitetura e urbanismo. O grupo possui atuação ativa em ARIS, como São Sebastião, em estudos preliminares até projeto executivo. Dentro da mesma instituição existe, ainda, o ATHOS (Assessoria Técnica para o Habitar de Origem Social), grupo acadêmico com atuação na comunidade.

O Morada de Luz é um projeto de extensão do curso de AU do Centro Universitário de Brasília (UniCEUB) que, atualmente, engloba estudantes e professores dos cursos de engenharia civil, psicologia e direito. O projeto de extensão nasceu em novembro de 2018, iniciando os trabalhos em um acordo com a CODHAB, atuando no Sol Nascente para realização de estudo preliminar de residências para o programa Lote Legal. 


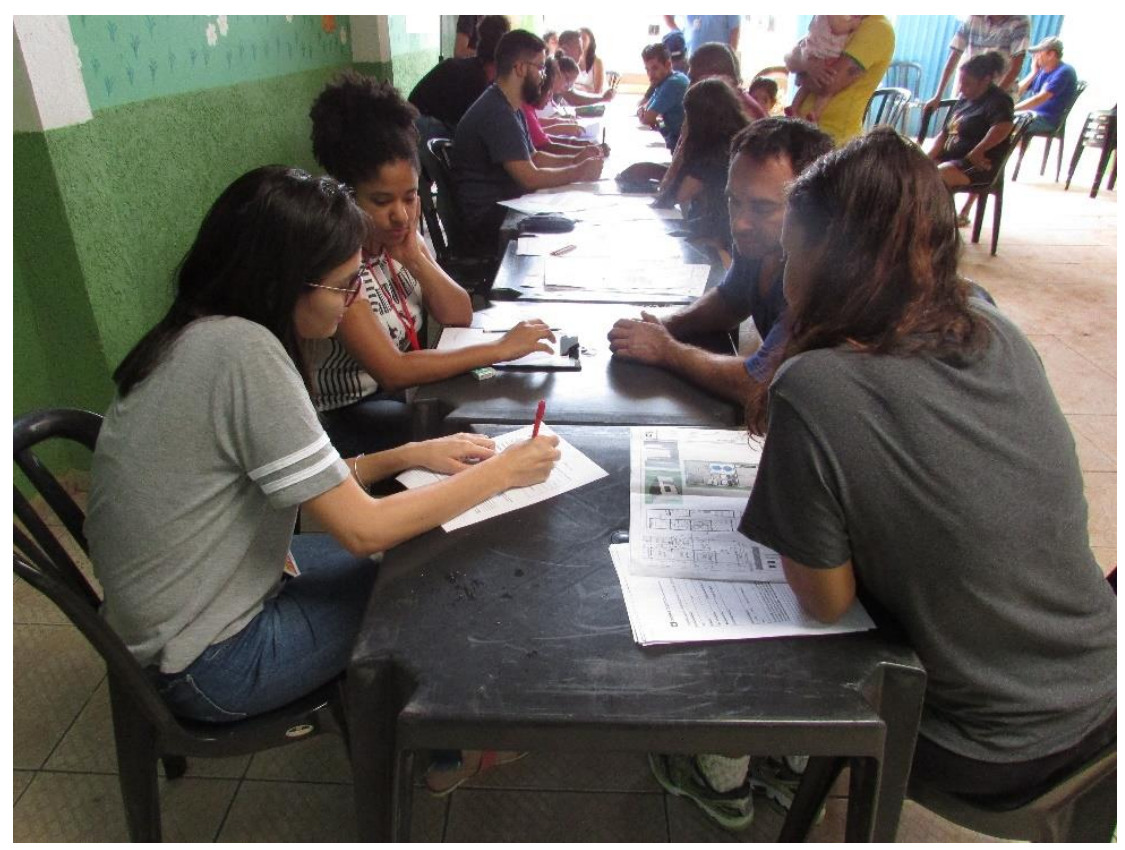

Figura 01 - Reunião projeto de extensão Morada de Luz e CODHAB no Sol Nascente em 2018

A atuação do grupo de estudantes e professores cresceu em 2019 em quantidade de colaboradores, sendo possível, portanto, a ampliação no campo de atuação. O segundo semestre de 2019 foi marcado pelo início dos projetos independentes em Planaltina-DF, em Área de Regularização de Interesse Social (ARIS). Neste segundo conjunto de projetos desenvolvidos desde o estudo preliminar até o acompanhamento de obras que já estão em andamento. O Projeto de Iniciação Científica em questão nasceu dentro do Projeto de Extensão.

Por último, existem coletivos de arquitetos, engenheiros e outros profissionais que contribuem com ATHIS no DF. Dentre esses, o coletivo Panã Arquitetura Social, formado por duas arquitetas em um mutirão de autoconstrução e que conta com mais de 15 colaboradores, representando como ação da sociedade civil que contribui para o cenário de assistência técnica.

O coletivo realizou projetos e acompanhamento de obras em áreas de zonas de interesse social-realizados por mutirões organizados em conjunto com as lideranças dos assentamentos-. Enquanto projeto, a inserção dos profissionais no ambiente foi de maior importância para compreensão das reais necessidades, assim como estabelecer vínculo com os clientes. A fase de construção com a participação tanto de profissionais quanto dos próprios moradores exemplifica a teoria de Imai (Villa, Ornstein, 2013) de que a participação de ambas as partes em todas as fases determina a qualidade construtiva e o nível de realização dos moradores com a própria casa. 
Além da atuação independente, o coletivo Panã e o projeto de extensão Morada de Luz atuam em parceria em Planaltina-DF, responsáveis por projetos de arquitetura, consultoria técnica e acompanhamento de obra. A ação foi idealizada e realizada com intuito de atingir localidades sem atuação da companhia responsável por habitação no Distrito Federal, como constatado nos registros a seguir.

Por fim, a Jornada de Assistência Técnica de Habitação de Interesse Social (JATHIS) organizada por arquitetos e urbanistas do IAB-DF em conjunto com o CAU-DF e com apoio de outras instituições, ocorre uma vez por ano desde 2017 e tem como objetivo levar os estudantes e profissionais a conhecer a atuação em HIS como intervenções habitacionais e urbanas. Em 2020 formaram-se as turmas de Capacitação, além da formação de grupos relacionados a ATHIS a partir dos eventos. 


\section{MÉTODO}

A pesquisa foi estruturada em três principais métodos de pesquisa: Revisão bibliográfica; Questionários; Levantamento e análise de dados secundários.

A pesquisa bibliográfica buscou, em primeiro plano, a contextualização da situação habitacional do Brasil e, principalmente de Brasília. Seguido pelo acervo de históricos de assistência técnica desenvolvidos no país e os tipos de intervenções que ocorrem. Por fim, compreender a APO, suas metodologias e termos associados- como a Psicologia Ambiental.

Inicialmente, pretendia-se realizar Avaliação Pós-Ocupação de moradias atendidas por ATHIS de diferentes formas. Entretanto, dado o contexto de pandemia e a impossibilidade de realização de ações presenciais, tornou-se inviável a realização de pesquisa de campo com as famílias atendidas. A pesquisa foi, então, adaptada ao formato virtual, incluindo dados secundários voltados às demandas e atendimentos em ATHIS e questionário online, para compreensão da percepção dos processos e resultados de ATHIS por parte de estudantes e profissionais da área de construção civil.

Em relação ao questionário online, o objetivo foi, através de perguntas de múltipla escolha e abertas, compreender entre os envolvidos na área de construção civil o nível de contato com ATHIS -tanto acadêmico, caso existe, quanto profissional e o interesse-. Inicialmente, foram questionadas as informações pessoais, dados profissionais, como idade, local de nascimento e local de moradia, em seguida, foram colhidas as informações profissionais, área de formação, tempo de atuação, e, ainda, a percepção individual com relação à atuação em assistência técnica, quais fatores de maior relevância, desafios e comentários abertos ao tema.

Os dados secundários foram levantados junto à:

1. Redes sociais: pesquisas de agentes e entidades que atuam com ATHIS no DF;

2. Pesquisa Distrital de Amostra de Domicílios (PDAD), foram levantadas as cidades com menor renda per capita e com maior número de pessoas em déficit habitacional, especialmente devido à inadequação habitacional.

3. Demanda de atendimento em ATHIS: Dados da Companhia de Desenvolvimento e Habitação do Distrito Federal (CODHAB) permitiram a compreensão da distribuição espacial de demandas de atendimento, através do CEP dos moradores inscritos no 
programa de melhorias habitacionais, utilizando-se a localização aproximada por bairro-quadra-rua/conjunto.

4. Dados de obras já realizadas pela CODHAB em Porto Rico, Santa Maria. Os registros foram realizados pela equipe de arquitetos e assistentes sociais da Companhia com os moradores selecionados para participar do programa Melhorias Habitacionais.

5. Dados de atuação profissional registrada do Conselho de Arquitetura e Urbanismo (CAU): Dados de Registro de Responsabilidade Técnica (RRT) emitidos e resguardados pelo Conselho de Arquitetura do Distrito Federal (CAU-DF), permitiram compreender o conjunto de informações presentes em cada RRT emitida, foram feitas análises distintas. A primeira em um mapeamento por endereço ou CEP de registros simples e mínimos - o primeiro tipo engloba construções e reformas gerais enquanto as RRTs mínimas são exclusivas para habitações em até $70 \mathrm{~m}^{2}$ ou conjunto habitacional de interesse social-; e, em segunda análise, o recorte temporal entre os anos de 2014 até abril de 2020. 


\section{RESULTADOS E DISCUSSÃO}

\section{LEVANTAMENTO E ANÁLISE EM REDES SOCIAIS}

Em busca de compreender melhor o cenário habitacional no DF e seus agentes, as redes sociais foram utilizadas como recursos para a compreensão dos agentes ativos de iniciativas de ATHIS. Um levantamento realizado entre 18/10/2019 e 20/11/2020 identificou no Instagram, rede de compartilhamento de imagens e vídeos, não foram encontrados resultados relacionados à arquitetura social nas seguintes tags: \#lei11888 \#assistenciatecnica. As postagens encontradas com a \#athis foram de $34 \%$ criadas pelos Conselhos de Arquiteturas Nacional e das unidades federativas; mais de 14\% -representando 6 postagens, provenientes de empresas privadas; e as demais tiveram como autoria arquitetos independentes, ONGs, estudantes, pesquisadores, projetos de extensões universitárias e sindicatos. A amostra total foi de 41 resultados em todo Brasil.
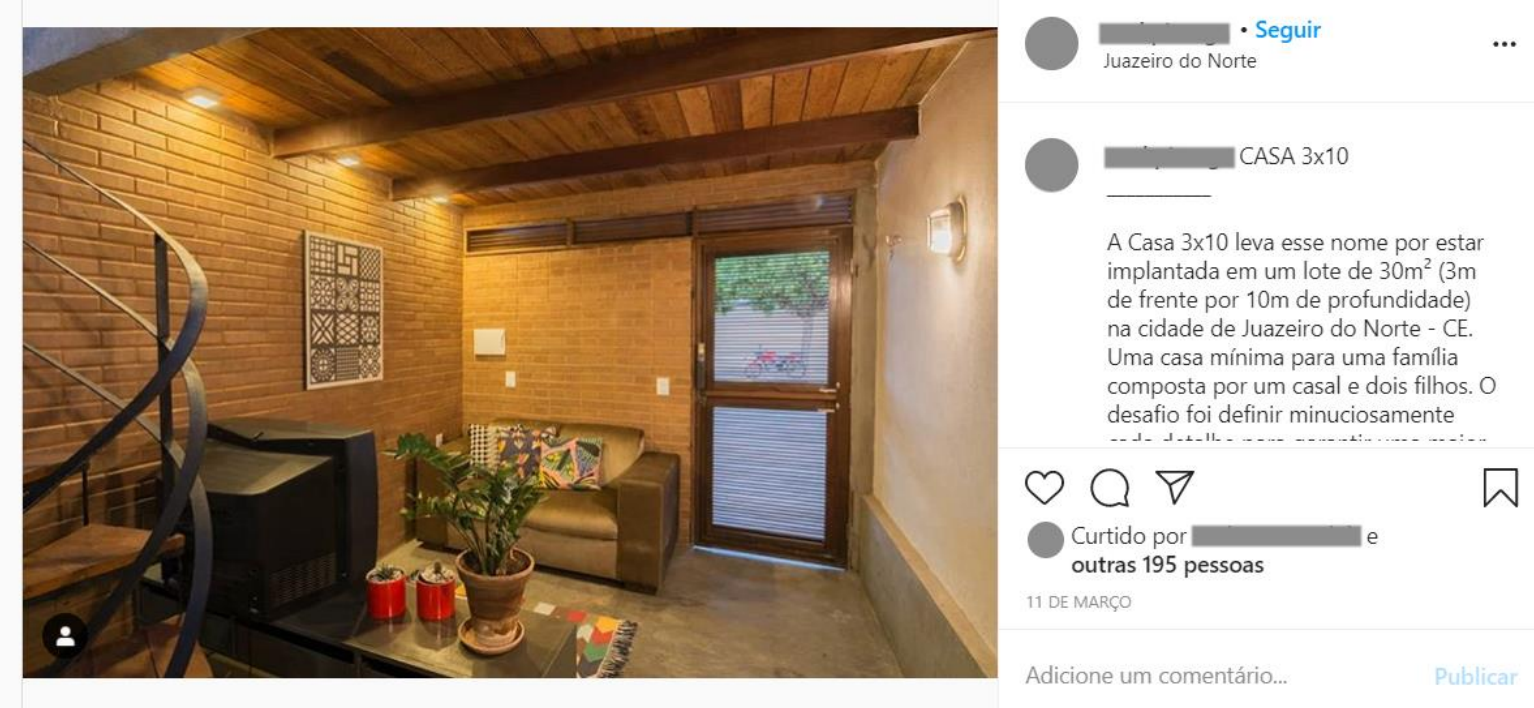

Figura 02 - Postagem resultado da \#athis

A busca de \#habitaçãosocial, encontrou maior volume de postagens e de procedências distintas das encontradas no ano anterior, em 1 mês foram relacionadas 141 publicações em todo território nacional. Parte das postagens estavam vinculadas às eleições municipais em forma de propaganda política de candidatos; outro grupo de pessoas foi de divulgação de obras e projetos profissionais de ATHIS; portfólio acadêmico de estudantes voltados à habitação social; e, por fim, divulgação de projetos de arquitetura realizados para concursos. Os Conselhos de Arquitetura seguem ativos nas redes. 
Apesar do maior número de publicações no ano de 2020, dentre as mais recentes não aparecem relação com o DF, enquanto as postagens de \#athis de 2019 encontram Brasília, mas se restringem ao CAU-DF, página da Jornada de assistência técnica de habitação de interesse social (JATHIS), evento financiado e organizado pelo CAU-DF e IAB-DF, e do Projeto de Extensão do UniCEUB, o Morada de Luz.

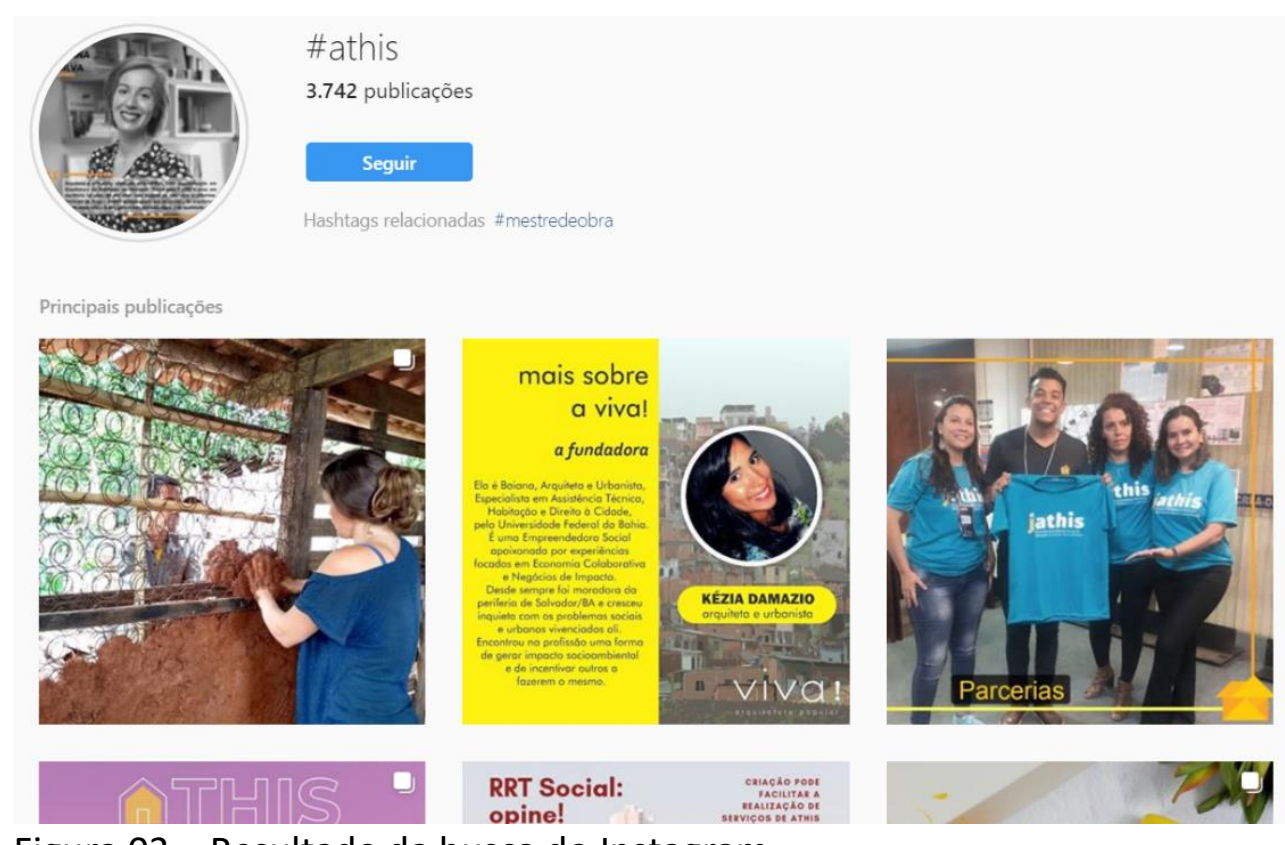

Figura 03 - Resultado da busca do Instagram

\section{COMPANHIA DE HABITAÇÃO DO DISTRITO FEDERAL}

Ao buscar iniciativas privadas de ATHIS no DF, são encontrados poucos escritórios ou arquitetos autônomos voltados ao público de HIS. Em escala maior são vistos concursos organizados por empresas públicas de edificações de interesse popular, intervenções urbanas em áreas de risco ou problemas socioespaciais -como o edifício de habitação coletiva em Samambaia, área de ARIS. Portanto, os projetos de arquitetura e intervenção urbana concentram-se majoritariamente na Companhia de habitação de Brasília (CODHAB).

Em um levantamento realizado pela CODHAB, dentro de um universo amostral de 50 famílias que receberam assistência técnica em Porto Rico -bairro de Santa Maria-, percebe-se que várias das residências contempladas estavam em situações de coabitação- mais de um núcleo familiar no mesmo lote ou unidade habitacional- e adensamento populacional número de cômodos na casa insuficiente para a quantidade de moradores. Além disso, em regiões periféricas em que as condições de reforma e adaptação das moradias são escassas, 
encontram-se problemas relacionados à acessibilidade para portadores de necessidades especiais, idosos e crianças. A pesquisa com os moradores da área em questão encontrou 7 dentre as 50 famílias que encontram em suas residências dificuldade de acessibilidade.

As famílias habilitadas e receber o programa de melhorias estavam inseridas em realidades sem infraestrutura básica, como rede de água encanada e caixa d'água. Portanto, poucas propostas não envolveram intervenções nas instalações hidrossanitários. Banheiros e impermeabilização de paredes foram pontos desenvolvidos em mais de $80 \%$ dos projetos das residências. Junto a esses fatores houveram propostas de intervenções na estrutura existente, problema recorrente às moradias provenientes de autoconstrução sem profissional especializado.

\begin{tabular}{|c|c|}
\hline 1,34 & famílias por lote \\
\hline 1,12 & famílias por unidade habitacional \\
\hline 5,2 & cômodos na unidade habitacional \\
\hline 4,08 & moradores por unidade habitacional \\
\hline $14 \%$ & das UH apresentam alguma morador PNE \\
\hline $98 \%$ & das UH apresentavam rede de água encanada antes da intervenção \\
\hline $92 \%$ & das UH apresentavam rede elétrica antes da intervenção \\
\hline $84 \%$ & das UH apresentavam rede de esgoto antes da intervenção \\
\hline $80 \%$ & das UH apresentavam rede de coleta de lixo convencional antes da intervenção \\
\hline $14 \%$ & das UH apresentavam caixa d'água instalada antes da intervenção \\
\hline $4 \%$ & das UH apresentavam rede de água encanada antes da intervenção \\
\hline $72 \%$ & das UH apresentavam paredes em bloco cru antes da intervenção (sem reboco) \\
\hline $16 \%$ & das UH estavam abaixo do nível da rua antes da intervenção \\
\hline
\end{tabular}

Tabela 01 - Dados de APO realizado pela CODHAB em Porto Rico (Santa Maria)

Fonte: CODHAB, 2020.

Para entendimento do processo, todas as etapas foram acompanhadas por, no mínimo, um arquiteto responsável. Além disso, as obras foram supervisionadas pelas equipes da CODHAB e realizadas por empresas contratadas para tal. Dessa forma, o contexto do atendimento e realização de projeto individualizado, apesar de não ser realizado em grande escala e com rapidez, torna-se mais eficaz para o problema de habitação encontrado.

Mencionado por Imai (Villa, Ornstein, 2013), os complexos de moradias padronizados resolvem principalmente para os moradores que construiriam de forma corrompida. Isto é, 
enquanto solução atende apenas as situações de precariedade extrema -envolvendo estruturas corrompidas que poderiam colocar em risco a vida dos habitantes-e algumas situações de coabitação e adensamento excessivo, considerando que as regiões de implantação dos complexos do Programa Minha Casa Minha Vida encontram-se distantes dos centros.

Os programas de atendimento individualizado, como o $\mathrm{MH}$ da CODHAB, tendem a resolver as questões prioritárias, chegando, ainda, em um acordo entre as partes profissionais e o morador sobre as necessidades principais da residência. Além do orçamento limitante, o contato entre arquiteto e cliente revela questões profundas aos moradores, como a relação entre este e a sua residência -já que a maior parte provém de autoconstrução ou construção por um familiar-. As análises da residência e necessidades realizada por ambas partes e conhecendo o histórico familiar, assim como o conhecimento do local permitem o enquadramento das prioridades em obra.

\begin{tabular}{|l|l|}
\hline $52 \%$ & de cômodos criados \\
\hline $44 \%$ & de cômodos remanejados \\
\hline $14 \%$ & de caixa de água executadas \\
\hline $32 \%$ & de cômodos ampliados \\
\hline $88 \%$ & de execuções de paredes \\
\hline $6 \%$ & de demolições significativas \\
\hline $88 \%$ & de instalações de esquadrias \\
\hline $36 \%$ & de execuções de poço de ventilação \\
\hline $78 \%$ & de paredes impermeabilizadas \\
\hline $86 \%$ & de intervênções nas estruturas \\
\hline
\end{tabular}

Tabela de modificações realizadas em Porto Rico (Santa Maria)

Fonte: CODHAB, 2020

No caso em estudo no bairro de Santa Maria, apenas uma obra obteve demolição de paredes e estrutura de forma significativa, isto é, em 49 residências as plantas originais foram mantidas. Anteriormente, foi visto que as unidades habitacionais possuem em média 5 cômodos por residência e ao retirar os ambientes de áreas molhadas -banheiro e cozinhapermanecem apenas uma sala e dois quartos. Dessa forma, entre as intervenções 26 
aumentaram o número de cômodos na casa, enquanto 22 famílias apenas reestruturam seus ambientes existentes.

Entre a infraestrutura das residências foram concentrados esforços em mais de $80 \%$ de todas as casas. As intervenções e readequações estruturais estiveram presentes em 43 obras, enquanto a instalação de esquadrias -portas e janelas- representam 44 do total. Completa-se os quatro pontos de maior número de intervenção com as obras em instalações elétricas e resolução dos problemas de coberturas existentes que representam, respectivamente, 41 e 42 obras.

\begin{tabular}{|l|l|}
\hline $82 \%$ & de intervenções na rede eléctrica existente \\
\hline $80 \%$ & de intervêncões na execução de cobertuar existente \\
\hline $66 \%$ & de intervênções em banheiro existente \\
\hline $56 \%$ & de intervênções na cozinha \\
\hline $64 \%$ & de paredes revestidas com reboco \\
\hline $60 \%$ & de paredes revestidas com revestimento cerâmico \\
\hline $48 \%$ & de paredes pintadas do piso ao forro \\
\hline $68 \%$ & de colocação de piso cerâmico \\
\hline $34 \%$ & de execução de aterro \\
\hline $6 \%$ & de adaptação em banheiros existente \\
\hline $4 \%$ & de adaptações para acessibilidade de PNE (rampas,etc) \\
\hline
\end{tabular}

Tabela de modificações realizadas em Porto Rico (Santa Maria)

Fonte: CODHAB, 2020

Por fim, os dados encontrados acima de residências com tipologias e implantação parecidas poderiam ser visualizados como oportunidade de criar intervenções gerais. No entanto, os registros dos levantamentos comparados aos resultados pós obra revelam as necessidades especificas de cada cliente, incluindo as adaptações de acessibilidade -presente em 2 duas famílias- e as necessidades de demolições expressivas, em apenas 3 obras.

\section{DEMANDA DE ATENDIMENTO EM ATHIS}

O mapeamento realizado a partir dos dados de demandas do Programa Melhorias Habitacionais da CODHAB permite a constatação de que o lado oeste carece dos serviços de 
assistência técnica. Apenas Taguatinga, Ceilândia e Samambaia, onde situam-se a maior parte dos pedidos, abriga um terço dos habitantes do DF -somando mais de 850 mil moradores-. Segundo o PDAD 2018, a população residente nessa região faz parte do setor

Além da alta densidade populacional na região, a CODHAB atua ativamente dentro do Sol Nascente, Pôr-do-Sol e Ceilândia, sendo o acesso ao serviço com maior ampliação e divulgação. A atuação da Companhia de Habitação gera, portanto, dois efeitos significativos dentro das comunidades. O primeiro é de tratar o problema de moradia nas regiões de maior demanda, considerando a concentração populacional, enquanto, em segundo lugar, também há um movimento de conscientização do direito ao serviço existente.

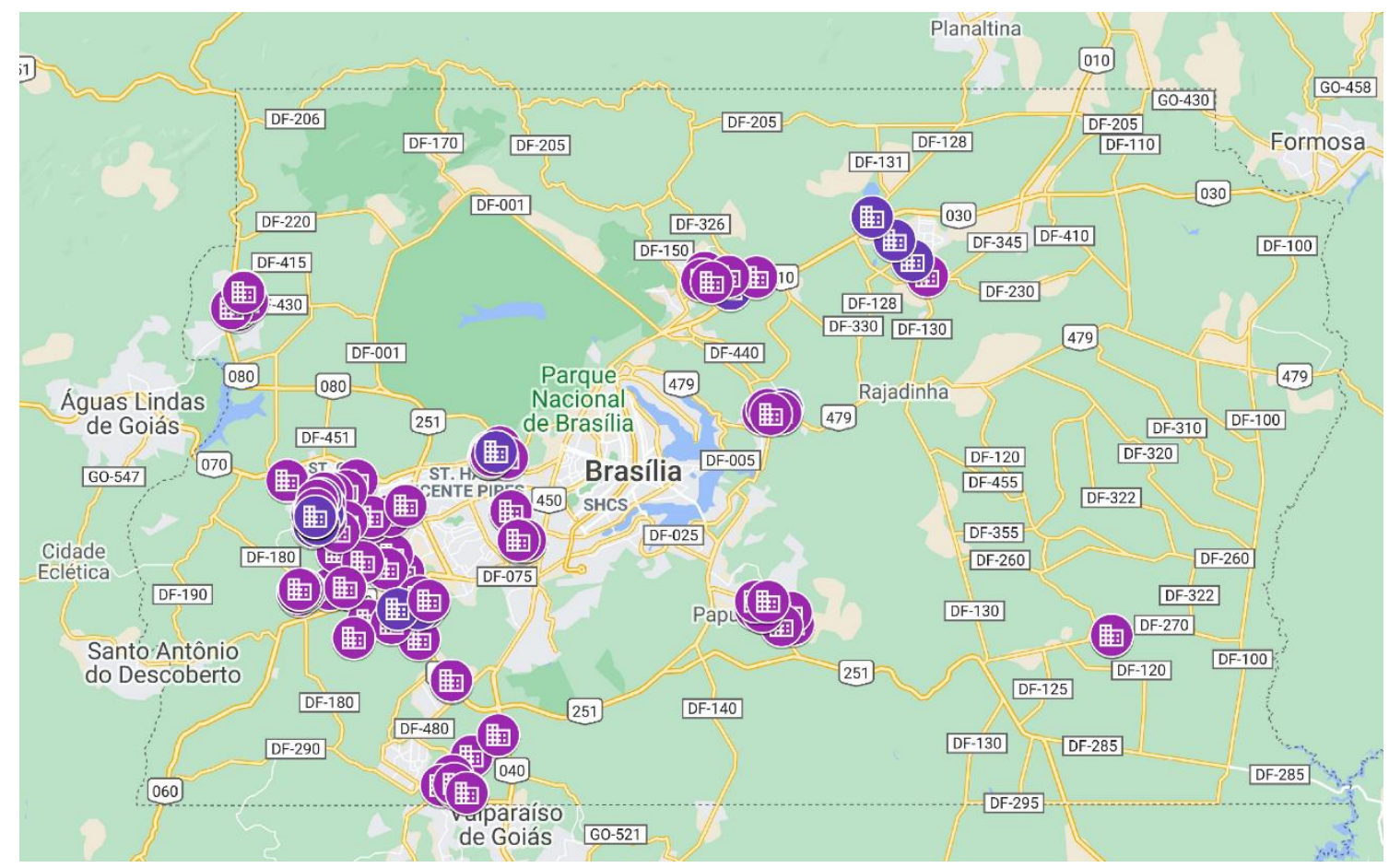

Mapa 01 -Demandas do programa Melhorias Habitacionais por CEP.

Fonte:https://www.google.com/maps/d/u/1/viewer?mid=1llDcmqyfWtGRYbWdtiVCcyXtSnT nbhio\& $\|=-15.820797820955567 \% 2 C-47.85179669999998 \& z=10$

O mapa apresenta endereços por CEP e locadas com detalhe máximo de rua ou quadra. Dentre os candidatos ao programa de Melhorias Habitacionais $(\mathrm{MH})$ é possível compreender o movimento mencionado de divulgação entre os próprios moradores. Em locais dentro do Sol Nascente houveram ruas com 20 cadastros, enquanto locais com menor quantidade de candidaturas, como Planaltina, também foram concentrados em distâncias de 3 ruas. 
A localidade de maior candidatos foi, com mais de 50 cadastros, o Sol Nascente. Isso se deve à alta concentração populacional, com quase 80 mil habitantes (PDAD 2013), foi desmembrada da Ceilândia em 2019 e tornou-se uma Região Administrativa independente junto ao Pôr-do-Sol. Ambas regiões tiveram em suas localidades, a implantação dos Postos de Atendimento da CODHAB.

A presença da Companhia de Habitação e o clima de debate sobre direito à moradia aproxima o tema dos moradores a partir da possibilidade de participar e beneficiar-se dos programas apresentados. Além disso, os concursos para edificações residenciais e institucionais auxiliam no crescimento da temática. São, portanto, aglomerados os chamados por atividades de ATHIS em áreas de atuação prévia. Diante disso, Sol Nascente, Pôr-do-Sol, Samambaia e Riacho Fundo são as RAs com maiores quantidades de famílias em demanda.

As áreas citadas acima obtiveram, nos últimos 5 anos, segundo as emissões de Registro de Responsabilidade Técnica, uma quantidade razoável de atendimentos, ainda insuficientes frente à alta demanda. Entretanto, outras áreas afastadas das RAs citadas anteriormente acabam por sofrer da escassez de serviços voltados a HIS. Planaltina e Sobradinho representam áreas de alto déficit habitacional, posicionadas entre terceiro e sétima posição entre as regiões administrativas. A coabitação segue como problema principal entre a região, no entanto, em Sobradinho II, a terceira colocação, cresce a precariedade das habitações, gerada pelo desenvolvimento de comércio e regularização de áreas de condomínio.

Para as localidades acima, as ações da sociedade civil e de instituições compreendem parte das iniciativas de ATHIS que os moradores entram em contato. Dessa forma, a atuação e mobilização recente de grupos acadêmicos, coletivos de arquitetos e as próprias instituições são de extrema importância e urgência.

\section{DADOS DE ATUAÇÃO PROFISSIONAL REGISTRADA}

A análise aconteceu, sobretudo, por dados cedidos por instituições, como o Conselho de Arquitetura do Distrito Federal (CAU-DF) e pela CODHAB, devido ao cenário pandêmico. A colaboração do CAU-DF permitiu acesso às quantidades de RRTs (registro de responsabilidade técnica) emitidas entre os anos de 2015 a abril de 2020 -recorte escolhido devido à atuação da CODHAB nas emissões do registro técnico.

Os dados obtidos permitiram a compreensão dos projetos e obras realizados e registrados com acompanhamento profissional, considerando que as RRTs são emitidas 
apenas por arquitetos ou engenheiros que realizaram projeto ou iniciarão a obra. Dessa forma, foram colhidas duas modalidades de registro, filtradas a partir das RAs do projeto e, ainda, passaram por pente fino no Google Maps, plataforma utilizada para criação do mapa, e análise do local.

As RRTs são divididas em quatro tipos, enquadradas destas formas, de acordo com o CAU-BR são: 1) RRT Simples, utilizadas para casos de gestão, vinculado ao acompanhamento de obra, compatibilização de projetos e outros; 2) RRT múltiplo mensal, para atividades executadas de forma avulsa e descontínua, permitindo a presença de mais de um profissional, com a condição que as visitas ocorram em um mesmo mês. 3) RRT mínimo, de exclusividade de habitações em até $70 \mathrm{~m}^{2}$ ou conjunto habitacional de interesse social. 4) RRT derivado, modalidade gratuita, serve para complementar ou acrescentar uma atividade em um registro existente.

A partir do ano de 2020, as RRTs mínimas podem ser utilizadas para até 100 casas de até $80 \mathrm{~m}^{2}$, todas voltadas à ATHIS, em um mesmo registro e arquiteto. A nova regra age como forma do CAU incentivar que as reformas e construções sejam registradas e acompanhadas por profissionais. A análise dos dados presentes não poderá contar com esses números pela data de colheita.

Entre as categorias citadas, os dados de RRT mínima são as principais em análise de ATHIS, no entanto, dentre os registros feitos pelos arquitetos existem ruídos usados para reformas ou ampliações habitacionais de pequeno porte, precisando, assim, da complementação da localidade do registro. Ainda assim, vários registros são emitidos como simples, incluindo a CODHAB emite dessa forma. Criado o recorte de tipos de RRT e localidades de ARIS, foram encontrados a quantidade de registros emitidos por cada RA. 


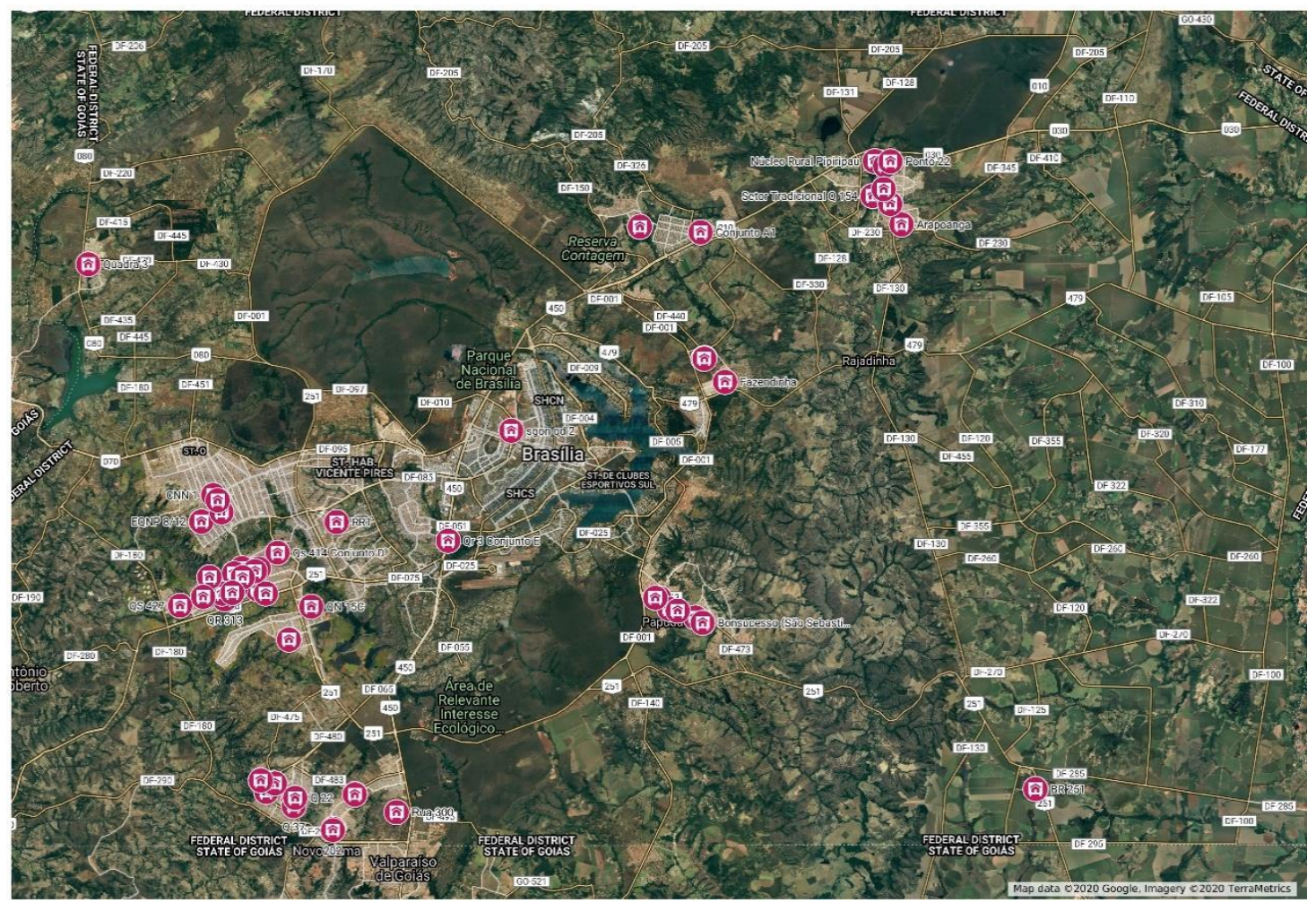

Mapa 02- Emissões de RRTs por endereço.

Fonte:https://www.google.com/maps/d/u/1/edit?mid=1IIDcmqyfWtGRYbWdtiVCcyXtSnTnb hio\& $\|=-15.867841380424094 \% 2 C-48.00835187578123 \& z=12$

Acima são observadas a repetição de concentração na área que se encontra Sol Nascente, Ceilândia e Samambaia, esperados devido à atuação da CODHAB. Apesar das localidades repetidas entre o primeiro mapa -de demandas por ATHIS- e as emissões de RRTs, a proporção encontrada é menor do que comparada às demandas pelo Programa de Melhorias Habitacionais. Apesar do maior número de intervenções em Planaltina, não é possível afirmar que se trata de assistência técnica.

Enquanto as regiões do Sol Nascente e Pôr-do-Sol são áreas novas da população afastada dos centros, em Planaltina a lógica não funciona da mesma forma. Os centros são misturados e áreas de ARIS, como Arapoanga, não são homogêneas enquanto população.

\section{QUESTIONÁRIO}

O questionário realizado online foi destinado a profissionais e estudantes envolvidos com a construção civil, diretamente ou indiretamente. Inicialmente, foram questionados dados pessoais. Entre os colaboradores, apenas cinco eram homens e as 26 participantes 
mulheres. Entre os participantes, 54,5\% são enquadrados na faixa etária entre 18 e 30 anos e em seguida, correspondendo a $22 \%$, entre 31 e 40 anos.

Qual gênero se identifica?

31 respostas

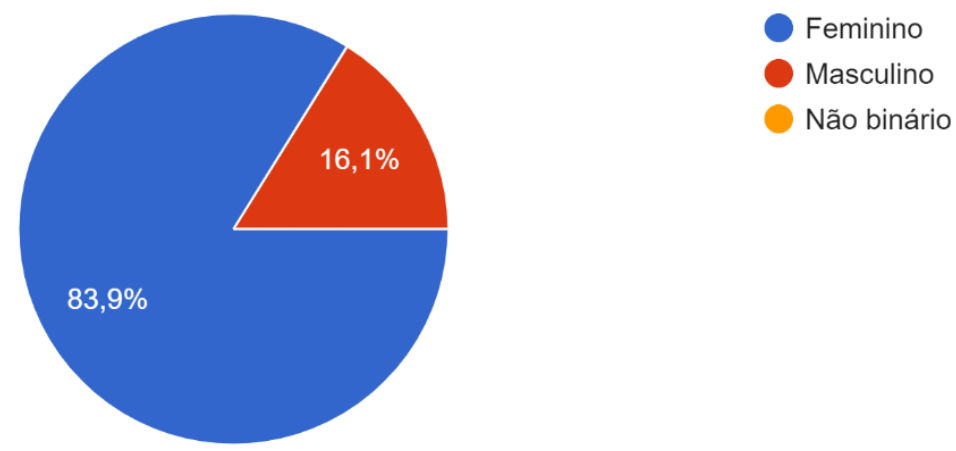

Tabela Google formulário - resultado gênero

Qual desses grupo de faixa etária você se enquadra?

31 respostas

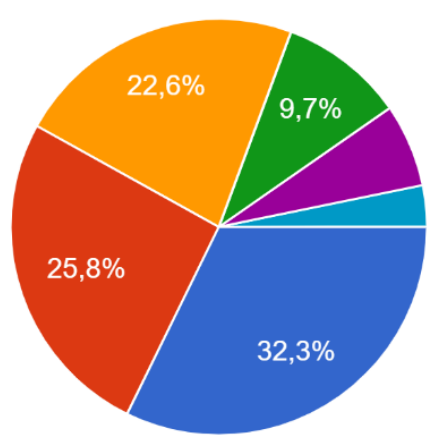

Entre 18 e 25 anos

Entre 26 e 30 anos

Entre 31 e 40 anos

Entre 41 e 50 anos

Entre 51 e 60 anos

Mais de 61 anos

Tabela Google formulário - resultado faixa etária

Entre os colaboradores, mais da metade são nascidos em Brasília, mas aparecem nas respostas, em ordem de quantidade: Pernambuco, Bahia, Rio de Janeiro, Minas Gerais, Goiás, Sergipe, São Paulo e João Pessoa.

Enquanto as respostas anteriores foram regulares, as localidades de moradia foram diversificadas. O Plano Piloto liderou, seguido por Ceilândia, Águas Claras, fora do DF e Jardim Botânico. 
Você mora em qual localidade no DF e entorno?

31 respostas

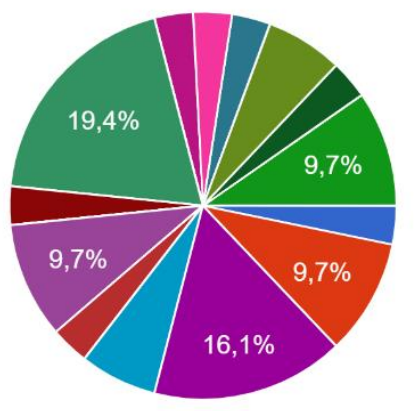

Arniqueira

Águas Claras

Brazlândia

Candangolândia

Ceilândia

Cruzeiro

Fercal

Gama

$1 / 5 \nabla$

Tabela Google formulário - resultado moradias dos entrevistados

Após a sequência de questões pessoais, foram colhidas as perguntas profissionais. Sendo mais de $66 \%$ dos participantes profissionais e os outros $33 \%$ estudantes, foram alcançados 31 profissionais de áreas variando de arquitetura e urbanistas, advogados, engenheiros civis, ambientais, florestais, agrônomos, designer, técnico em edificações e assistente social. Entre os participantes, $6 \%$ possuem formação técnica e estão ou obtiveram graduação de arquitetura e urbanismo.

Entre o espectro mencionado, prevaleceu os recém-formados, $48 \%$ dos entrevistados disseram ter até 2 anos de formação, enquanto os que atuam por mais de 10 anos compreenderam $22 \%$ do total.

Quanto tempo atua em sua área?

31 respostas

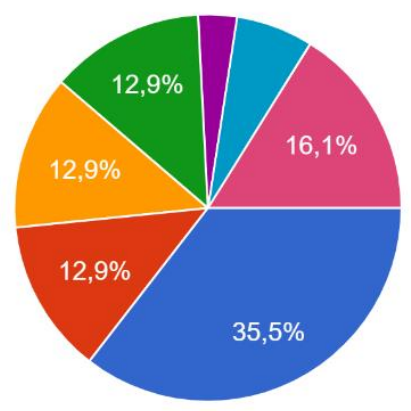

Até 1 ano

Entre 1 e 2 anos

Entre 2 e 3 anos

Entre 3 e 5 anos

Entre 5 e 10 anos

Entre 10 e 15 anos

Mais de 15 anos

Tabela Google formulário - resultado tempo de atuação

Ao seguir na área de Assistência Técnica de HIS, metade dos participantes relataram ter interesse na área, mas nunca ter atuado. Entre os profissionais e estudantes de arquitetura 
e urbanismo, todos os que nunca tiveram contato com ATHIS demonstraram interesse. Menos de $10 \%$ dos entrevistados disseram não ter interesse na área.

Entre o contato dos entrevistados, quando acadêmicos, mais de $60 \%$ respondeu que já estiveram em contato. Desses, quase $10 \%$ conheceram através de professores em suas matérias curriculares, $18 \%$ participou de projeto de extensão e outros participaram da JATHIS e/ou Capacitação em ATHIS realizada pelo IAB-DF.

Além disso, sobre contato em meio profissional, em $6 \%$ dos casos foi por meio de estágio na Companhia de Habitação do DF, casos pontuais de trabalhos em prefeituras de Campina Grande-Paraíba, coletivos e programas locais. Questionados sobre a área de atuação, $76 \%$ responderam trabalhar com projeto de arquitetura, $30 \%$ com obra, outros $33 \%$ em projetos de extensão.

Você tem atuação em ATHIS - Assistência Técnica em Habitação de Interesse Social?

31 respostas

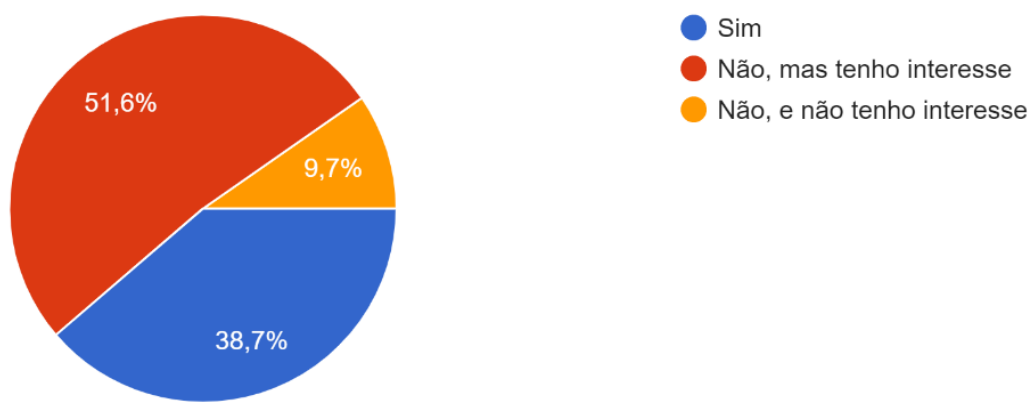

Tabela Google formulário - atuação em ATHIS e/ou interesse

Em sua vida PROFISSIONAL, você já teve contato, direto ou indireto, com iniciativas de ATHIS Assistência Técnica em Habitação de Interesse Social?

31 respostas

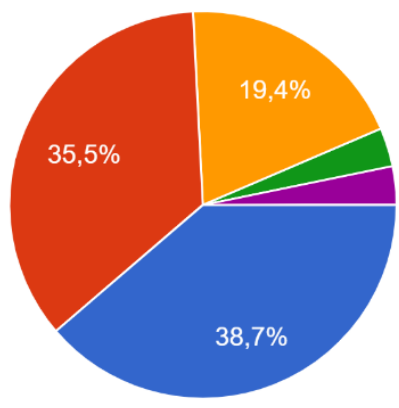

Não sou formado/a ainda

Como estudante de arquitetura conforme acima.

Indiretamente sim, conhecendo futuros moradores de projetos desenvolvidos por mim e visitando -os no pós entrega do empreendimento

Tabela Google formulário - contato com ATHIS em ambiente profissional 
A etapa final, sobre desafios e entendimento sobre ATHIS, questiona quais são as etapas mais importantes para um bom resultado, dentre os que responderam, $100 \%$ considerou levantamento de dados no local junto aos moradores de extrema importância, seguido de levantamento de dados físicos e planejamento orçamentário.

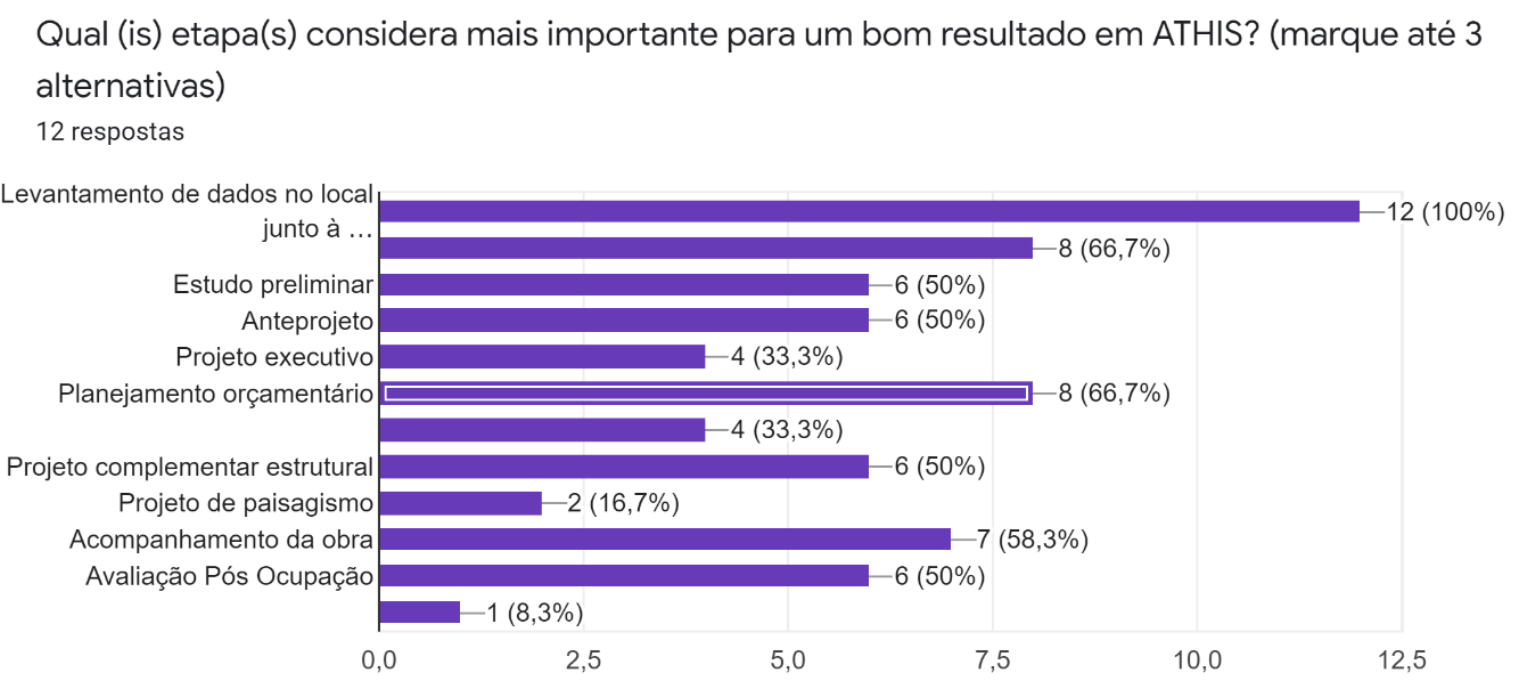

Tabela Google formulário - resultado enquete de resultados mais importantes em ATHIS

As respostas da última pergunta descreveram considerar a maior dificuldade adequar as necessidades das famílias ao orçamento limitado, assim como viabilizar o custo da execução. Por fim, descrevem as experiências recém descobertas de ATHIS importantes, assim como maior divulgação sobre o assunto, tanto para famílias com escassez de atendimento quanto aos profissionais da construção civil.

Dentre a coluna final, livre para observações adicionais ou comentários, chamam atenção que vários entrevistados descreveram as ações de ATHIS como pouco divulgadas e, em uma das observações, pouco reconhecida. Decorrente a novidade que ainda são as ações voltadas ao público profissional, tanto a atuação independente de coletivos e grupos quanto a Capacitação são sementes em crescimento.

Vale ressaltar que a divulgação aconteceu pelas redes sociais, grupos dos cursos de AU do Distrito Federal, plataforma do site e redes sociais do CAU-DF e, portanto, o público alcançado foi majoritariamente de estudantes e profissionais que recém descobriram a causa. Além desses, estudiosos e profissionais em atividade que estão retomando, em Brasília, a atuação com ATHIS, mas que possuem experiência prévia em outros estados. A partir da mesma coluna foram deixados contato para participação de atividades relacionadas a ATHIS e comentários de que existe a pretensão de aprofundamento no tema. 
Dentre os 2 profissionais que atuam exclusivamente com ATHIS, ambos consideram de extrema importância o levantamento de dados junto aos clientes, assim como o planejamento orçamentário da obra, considerando todos os aspectos de contexto. 


\section{CONSIDERAÇÕES FINAIS}

Entende-se como desproporcional as ações relacionadas a ATHIS e a demanda habitacional, em todo Brasil, e, com o crescimento exacerbado da população do Distrito Federal e entorno, na capital federal.

Em primeira análise é visível que as atividades atuantes de ATHIS são majoritariamente partidas pelas empresas públicas, no DF em especial. Além disso, a alta demanda em conjunto com o orçamento limitado dos clientes e do financiamento público tornam os projetos e obras.

É possível observar, desse modo, como a atuação da CODHAB dentro das comunidades possibilitou aos próprios moradores acesso e conhecimento aos serviços de ATHIS, portanto, sendo espelhado em emissões de registros técnicos particulares em grande quantidade nas áreas de atuação pública. Além dessa atuação de origem estatal, as ações e envolvimento de arquitetos, engenheiros e outros profissionais envolvidos com construção civil revelam interesse em ATHIS, dessa forma, podem ser percebidos nos últimos 5 anos ações dos Conselhos de Arquitetura, Institutos e faculdades. 


\section{REFERÊNCIAS}

BONDUKI, Nabil. Origens da habitação social no Brasil. Arquitetura Moderna, Lei do inquilinato e Difusão da casa própria. São Paulo. Editoria Estação Liberdade, 2013.

SOBREIRA, Fabiano. Brasília: Estratégias de não planejamento. 2013. Disponível em: https://www.vitruvius.com.br/revistas/read/minhacidade/13.152/4691 Acesso: 27/10/2020 CORREIA, Ludmila. Conforto Ambiental e suas relações subjetivas. Análise ambiental integrada na habitação de interesse social. Brasília. 2010

VILLA, Simone; ORNSTEIN, Sheila. Qualidade Ambiental na Habitação. Avaliação pósocupação. São Paulo. 2013.

CORREIA, Ludmila; MARINHO, Sandra; MIGUEL, Leticia .Capacitação em assistência técnica em habitação de interesse social no DF. VI Encontro da Associação Nacional de Pesquisa e Pós-graduação em Arquitetura e Urbanismo. 2020.

KALIL, Rosa Maria Locatelli. Avaliação pós-ocupação e eficácia social: estudo de caso comparativo de habitações de interesse social autoconstruídas na modalidade cooperativa autogestionária e na modalidade promoção pública municipal. Programa de Pós-Graduação em Engenharia - Faculdade de Arquitetura e Urbanismo, Universidade de Passo Fundo, Passo Fundo/RS. Passo Fundo: Universidade de Passo Fundo, 2004.

CORREIA, Ludmila. Conforto ambiental e suas relações subjetivas. Brasília. 2010. (203 pgs). Tese (Mestrado em Paisagem, Ambiente e Sustentabilidade) - Universidade de Brasília. KOWALTOWSKI, Doris C. C. K.; LABAKI, Lucila C.; PINA, Silva A. Mikami G.; SILVA, Vanessa Gomes da; MOREIRA Daniel de Carvalho; RUSCHEL, Regina C., BERTOLI, Stelamaris Rolla, FÁVERO, Edison e FILHO, Lauro L. Francisco. "Análise de parâmetros de implementação de conjuntos habitacionais de interesse social: ênfase nos aspectos de sustentabilidade ambiental e qualidade de vida." In: SATTLER, Miguel Aloysio e PEREIRA, Fernando Oscar Ruttkay. Construção e Meio Ambiente. Porto Alegre. ANTAC, 2006 (Coleção Habitare, v. 7, cap. 5)

LYNCH, Kevin. A imagem da cidade. 1997

MELO, Ana Luiza Novais de. A efetividade do programa de assistência técnica em habitações sociais no Sol Nascente - Distrito Federal. 2019. Programa de Pós-Graduação em Arquitetura e Urbanismo - Faculdade de Arquitetura e Urbanismo, Centro Universitário de Brasília, Brasília, 2019. 
Ferreira, Antônio Domingos Dias. Habitação de interesse social: Aspectos históricos, legais e construtivos. 1a ed. Rio de Janeiro: Interciência, 2015.

ZANCUL, Juliana de Senzi. Habitação estudantil: avaliação pós-ocupação em São Carlos-SP -

São Carlos-SP. 2007. Programa de Pós-Graduação em Arquitetura e Urbanismo - Escola de Engenharia de São Carlos da Universidade de São Paulo, São Carlos, 2007.

PDAD, 2015.

PDAD, 2018.

IBGE

Observatório territorial Seduh. http://www.observatorioterritorial.seduh.df.gov.br/ 